Article

\title{
Enzyme-Linked Immunosorbent-Assay for Deoxynivalenol (DON)
}

\section{Fang Ji, Hua Li, Jianhong Xu and Jianrong Shi *}

Institute of Food Safety, Jiangsu Academy of Agriculture Science (Key Lab of Agro-Food Safety and Quality, Ministry of Agriculture; Key Lab of Food Quality and Safety of Jiangsu Province-State Key Laboratory Breeding Base), Nanjing 210014, China

* Author to whom correspondence should be addressed; E-Mail: shiji@jaas.ac.cn; Tel.: +86-25-8439-2001; Fax: +86-25-8439-1260.

Received: 8 May 2011; in revised form: 28 June 2011 / Accepted: 14 July 2011 /

Published: 4 August 2011

\begin{abstract}
Deoxynivalenol (DON), one of the trichothecene mycotoxins, is a worldwide contaminant of wheat and barley, especially when infected by Fusarium graminearum, the causative agent of an epidemic wheat disease called Fusarium Head Blight. Because of the high risk of DON ingestion and the possibility of frequent exposure, it is important to develop a rapid and highly sensitive method for easy identification and quantification of DON in grain samples. In this study, we have developed an indirect competitive enzyme-linked immunosorbent assay (ELISA) to detect DON in wheat. We conjugated 3-O-Hemisuccinyl-DON (3HS-DON) to Bovine serum albumin (BSA) and Ovalbumin (OVA), and obtained DON-specific mice antisera. The indirect competitive ELISA revealed that the optimal concentration of mice serum and the coated antigen was $1 / 1600$ and $1 / 1500$, respectively. The antiserum cross-reacted with the trichothecenes 3-acetyl-DON and T-2 toxin, reaching about 55.2\% and 6.3\%, respectively, as compared with DON. Results showed that the assay could be performed satisfactorily using an extraction buffer containing less than $15 \%$ methanol. Recovery from DON was $82-93 \%$ in grains. The linear detection range of DON in grains was between 0.01 and $100 \mu \mathrm{g} / \mathrm{mL}$.
\end{abstract}

Keywords: Deoxynivalenol (DON); immunoassay; ELISA; Fusarium graminearum 


\section{Introduction}

Mycotoxins are toxic metabolites produced by fungi and are of considerable concern as they not only cause plant diseases but are also damaging to human and animal organs when contaminated food is ingested [1-3]. Deoxynivalenol (DON) is a common mycotoxin produced by some Fusarium species such as Fusarium graminearum and F. culmorum and is often found in small grains that have been infected with these Fusarium species. The most common small grain disease is called Fusarium head blight (FHB), which often develops following moist environmental conditions when the head is in flower.

The importance of DON to food safety is due to the severe effect that this mycotoxin has on animal systems. In 2003, the Council for Agricultural Science and Technology estimated the annual cost due to DON contamination of human food crops in the United States to be $\$ 637$ million [1]. DON can interfere with both protein and DNA synthesis in the cell. Symptoms exhibited by animals afflicted with trichothecene toxicoses include vomiting, feed refusal, diarrhea, and haemorrhaging of intestines and muscles [4]. DON has also been shown to be neurotoxic and immuno-suppressive [5]. Cell signaling pathways are activated by $1 \mathrm{mg} \mathrm{DON} / \mathrm{kg}$ body weight, through gene induction and activation of several nitrogen-activated protein kinases. DON ( $\geq 100 \mathrm{ng} / \mathrm{mL})$ activates hematopoetic cell kinase and double-stranded RNA-activated protein kinase, which leads to apoptosis [6]. The U.S. Food and Drug Administration (FDA) has set advisory DON levels for wheat-based foods and feeds of no more than $1 \mu \mathrm{g} / \mathrm{g}$ in finished human foods, $10 \mu \mathrm{g} / \mathrm{g}$ in poultry and ruminant feed, and $5 \mu \mathrm{g} / \mathrm{g}$ in other animal feeds [7]. Therefore, accurate determination of the presence of low amounts of DON is important in the surveillance of food and feed in order to maintain a high grain quality for food safety.

Fusarium trichothecenes have been classified into two structurally distinct groups, Type A and Type B, based on their oxygenation pattern [8]. Type A trichothecenes are generally more toxic than type B trichothecenes, suggesting the need to be able to detect type A from type B when analyzing a sample of grain [9,10]. Commonly used methods for the determination of DON include gas chromatography (GC), gas chromatography-mass spectrometry (GC/MS), high-pressure liquid chromatography (HPLC), and thin-layer chromatography (TLC), all of which involve considerable sample preparation, time involvement, and technical expertise [11-15]. The desire for low-cost, rapid, field-appropriate mycotoxin detection methods has led to several new developments [16]. These include enzyme-linked immunosorbant assay (ELISA) analysis, fluorescence polarization (FP), and non-instrumental immunoassays. Commercial kits using these technologies for DON detection in grains are available. These assays require little sample preparation, are rapid and relatively simple to execute, yet are sensitive [17-20]. Pestka et al. reported that ELISA could be used to analyze for DON in animal plasma and tissues without extensive clean-up [21].

To improve on these commercial kits, we wished to determine the optimal concentrations of antigen/antibody for DON detection as well as to test for the recovery of DON in artificially contaminated wheat samples. We report cross-reactivity studies with other Type B trichothecenes and show the levels of DON, and cross-reactive trichothecenes, that can accumulate in various Fusarium-infested wheat lines. 


\section{Materials and Methods}

\subsection{Materials}

Six-week-old BALB/c female mice were obtained from the Experimental Animal Center of Nanjing General Hospital and guinea pigs were from the Experimental Animal Center of Jiangsu Academy of Agricultural Sciences. DON, 3-acetyl-deoxynivalenol (3Ac-DON), T-2 toxin, Bovine serum albumin (BSA), ovalbumin (OVA), Freund's complete adjuvant, and Freund's incomplete adjuvant were from Sigma-Aldrich (Shanghai, China). 2,2-azinodi-ethylbenzothiazoline-sulfonice acid (ABTS) was from Roche (Shanghai, China). Goat anti-rabbit-IgG was from Invitrogen China. Derivatives of DON, 3-O-Hemisuccinyl-DON (3HS-DON), and the coupling proteins 3-HS-DON-BSA and 3-HS-DON-OVA, were synthesized in this lab based on the method of Casale [18]. The derivatives elicit an immune response whereas the smaller, non-derivatized DON will not.

\subsection{Immunization}

Six-week-old BALB/c female mice were injected intraperitoneally with 3HS-DON-BSA for immunization. Initial intraperitoneal inoculation was $100-250 \mu \mathrm{g}$ of the DON conjugate in $0.5 \mathrm{~mL}$ of Freund's complete adjuvant $(1: 1 / \mathrm{v}: \mathrm{v})$. Two more injections were carried out using Freund's incomplete adjuvant at intervals of four weeks each. Subsequent intraperitoneal booster inoculations followed at 2-week intervals consisting of $100-250 \mu \mathrm{g}$ of conjugate in $0.5 \mathrm{~mL}$ of saline. Guinea pigs were injected subcutaneously with 3HS-DON-BSA. All guinea pig injections were the same as for mice, with the exception of the dosage at 250-500 $\mu \mathrm{g}$. Emulsification of the antigen with the adjuvant was performed by an injector, whereby a syringe was used to draw up both the antigen and the adjuvant and emulsification occurred when the syringe plunger was moved up and down until the solution was well mixed.

\subsection{Specificity}

Four trichothecene mycotoxins, DON, 3Ac-DON, 15-acetyl-deoxynivalenol (15Ac-DON), and T-2 toxin, were tested for cross-reactivity (CR). We used indirect competition ELISA to determine the antibody titer and cross-reactivity. For the antibody titer, we selected the maximum dilution of antiserum when the enzymatic reaction was two times greater than the negative serum. At this antibody concentration, we added DON, 3-Ac-DON, 15-Ac-DON and T-2 toxin at different concentrations $(0.5 \mu \mathrm{g} / \mathrm{mL}, 5 \mu \mathrm{g} / \mathrm{mL}, 50 \mu \mathrm{g} / \mathrm{mL}, 500 \mu \mathrm{g} / \mathrm{mL}, 1000 \mu \mathrm{g} / \mathrm{mL}, 2000 \mu \mathrm{g} / \mathrm{mL})$, and the concentration of coating antigen (3-HS-DON-OVA) was $2.5 \mu \mathrm{g} / \mathrm{mL}$. We used the Abraham formula [19] to express the cross reaction:, $Y=(S / Z) \times 100$, where $\mathrm{S}$ is the concentration of standard antigen that causes $50 \%$ inhibition binding and $Z$ is the concentration of antigen analogues that causes $50 \%$ inhibition binding.

\subsection{Indirect Competitive ELISA Assay}

Immunoplates were coated with $100 \mu \mathrm{L} /$ well 3HS-DON-OVA dilution series (CBS, pH 9.6) and incubated overnight at $4{ }^{\circ} \mathrm{C}$. After washing three times with PBST, the immunoplates were incubated 
in a moist chamber for $1 \mathrm{~h}$ at $37^{\circ} \mathrm{C}$ and washed with PBST as described above. $100 \mu \mathrm{L}$ of DON, or the extraction of sample mixed with antisera 1:1 (v:v), was added to each well of the plates, incubated and washed as described above. Goat anti-rabbit-IgG was diluted 1:500 in PBS containing 1\% OVA and $100 \mu \mathrm{L} /$ well was added. After incubation in a moist chamber for $1 \mathrm{~h}$ at $37^{\circ} \mathrm{C}$, plates were washed three times with PBST and $100 \mu \mathrm{L} /$ well of ABTS substrate was added. Subsequently, plates were incubated at $37{ }^{\circ} \mathrm{C}$ for $15 \mathrm{~min}$. The reactions were stopped by adding $50 \mu \mathrm{L} /$ well of $2 \mathrm{M} \mathrm{H}_{2} \mathrm{SO}_{4}$, and the optical densities determined at $405 \mathrm{~nm}$ using an ELISA reader (Thermo Multiskan MK3).

\subsection{Optimized Working Concentration}

Working concentrations of coating antigens and antisera were optimized by using an indirect competitive ELISA format. The 96-well microtiter plate (Corning, USA) was coated with a series of concentrations of the coating antigen (3HS-DON-OVA), and a series concentration of antisera in Phosphate Buffered Solution (PBS) $\left(137 \mathrm{mM} \mathrm{NaCl}, 2.7 \mathrm{mM} \mathrm{KCl}, 8.1 \mathrm{mM} \mathrm{Na} \mathrm{HPO}_{4}, 1.76 \mathrm{mM}\right.$ $\mathrm{KH}_{2} \mathrm{PO}_{4}, \mathrm{pH}$ 7.4) was added. Starting with a concentration of $2000 \mu \mathrm{g} / \mathrm{mL}$ of $3 \mathrm{HS}-\mathrm{DON}-\mathrm{OVA}$, dilutions of 1/500, 1/800, 1/1000, 1/1500, 1/2000 were made in PBS. Antisera was diluted to 1/400, 1/800, 1/1600, 1/3200, 1/6400 in PBS. Absorbance at $405 \mathrm{~nm}$ was determined.

\subsection{The Effect of Methanol on Detecting DON by ELISA}

Reagent grade methanol was diluted in sterile distilled water to form different concentrations $(0-50 \%)$ of methanol. DON then was dissolved separately with the methanol dilution for the comparison of the effect of methanol to the ELISA.

\subsection{Preparation of Samples}

Four g of wheat sample were extracted with $20 \mathrm{~mL}$ of $10 \%$ methanol $(\mathrm{v} / \mathrm{v})$ in water on a rotary shaker for $1 \mathrm{~h}$, then centrifuged at $7000 \mathrm{rpm}$ at room temperature for $10 \mathrm{~min}$. The supernatant was used in the ELISA assays.

\subsection{Standard Curve}

Inhibition of DON was determined by the indirect competitive ELISA method. A series of DON concentrations $(0.001-1000 \mu \mathrm{g} / \mathrm{mL})$ were prepared by dissolving DON in PBS containing $10 \%$ methanol. The standard curve was built using Curve Expert (version 1.38; Daniel Hyams, Starkville, MS).

\subsection{Recovery Test}

DON was added $(0.5 \mu \mathrm{g} / \mathrm{g}, 10 \mu \mathrm{g} / \mathrm{g}, 200 \mu \mathrm{g} / \mathrm{g})$ to non-contaminated wheat, extracted as described above, and $100 \mu \mathrm{L}$ of supernatant was added to each well of a 3-HS-DON-OVA prepared plate. 


\subsection{Calculation of the Concentration of DON in Sample}

Concentration of DON $(\mu \mathrm{g} / \mathrm{g})=C \cdot V \cdot(1 / M) \cdot D$

$C$ : concentration of DON in the immunoplate well;

$V$ : volume of sample $(\mathrm{mL})$;

$M$ : weight of sample (g);

$D$ : dilution ratio.

\section{Results and Analysis}

\subsection{Titration of Antiserum}

In order to determine an antiserum titration curve, immunoplates were coated with 3HS-DON-OVA and a series concentration of antiserum was compared to a negative serum plate. A positive value for the ELISA was defined as the absorbance value $\left(\mathrm{OD}_{405}\right)$ of two-fold greater than the absorbance of the negative serum. As the antiserum titration curve (Figure 1) showed, the sensitivity of antibodies is clearly at 1:6400 dilutions for guinea pig serum and 1:12800 in mouse serum.

Figure 1. Indirect ELISA titration of Deoxynivalenol (DON), antiserum.

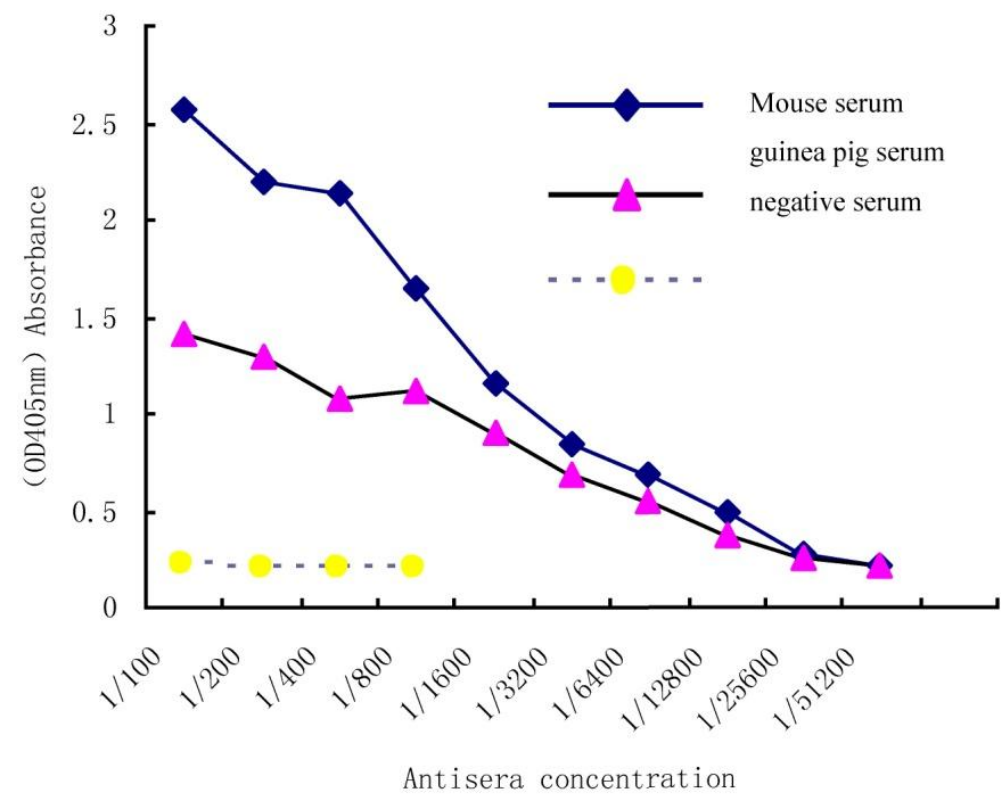

\subsection{Optimized Working Concentration}

The high titration of mouse antiserum was chosen for further experimentation. Several dilutions of the antiserum were titrated against different concentrations of the coating antigen to measure reactivity. The titer dilution of the antiserum was considered suitable when the $\mathrm{OD}_{405}$ value was around 1.0. We show in Table 1 that the optimized working concentration of coating-antigen and antiserum is 1:1500 and $1: 1600$, respectively. 
Table 1. Determination for optimal concentrations of coated antigen and antisera.

\begin{tabular}{cccccc}
\hline Coated Antigen & \multicolumn{5}{c}{ Antisera Concentration } \\
\cline { 2 - 6 } Concentration & $\mathbf{1 / 4 0 0}$ & $\mathbf{1 / 8 0 0}$ & $\mathbf{1 / 1 6 0 0}$ & $\mathbf{1 / 3 2 0 0}$ & $\mathbf{1 / 6 4 0 0}$ \\
\hline $1 / 500$ & 2.620 & 2.447 & 2.269 & 2.040 & 1.685 \\
$1 / 500$ & 2.590 & 2.421 & 2.231 & 2.006 & 1.654 \\
$1 / 800$ & 1.309 & 1.102 & 1.001 & 0.773 & 0.579 \\
$1 / 800$ & 1.297 & 1.000 & 0.934 & 0.737 & 0.503 \\
$1 / 1000$ & 1.187 & 1.093 & 0.964 & 0.770 & 0.513 \\
$1 / 1000$ & 1.382 & 1.041 & 0.926 & 0.734 & 0.539 \\
$1 / 1500$ & 1.448 & 1.222 & 1.059 & 0.884 & 0.629 \\
$1 / 1500$ & 1.536 & 1.239 & 1.074 & 0.808 & 0.682 \\
$1 / 2000$ & 1.508 & 1.210 & 1.124 & 0.900 & 0.648 \\
$1 / 2000$ & 1.520 & 1.262 & 1.100 & 0.940 & 0.673 \\
\hline
\end{tabular}

\subsection{Effect of Methanol Concentration on the Assay}

Methanol and water are often used to extract DON and we wished to determine whether the methanol can interfere with the antibody-antigen reaction. We used different concentrations of methanol in a reaction with antiserum of DON. Results (Figure 2) showed that $10 \%$ (and below) of methanol had no effect on the binding but once the concentration was higher than $20 \%$, the interference rapidly increased.

Figure 2. Effect of methanol concentration on the assay.

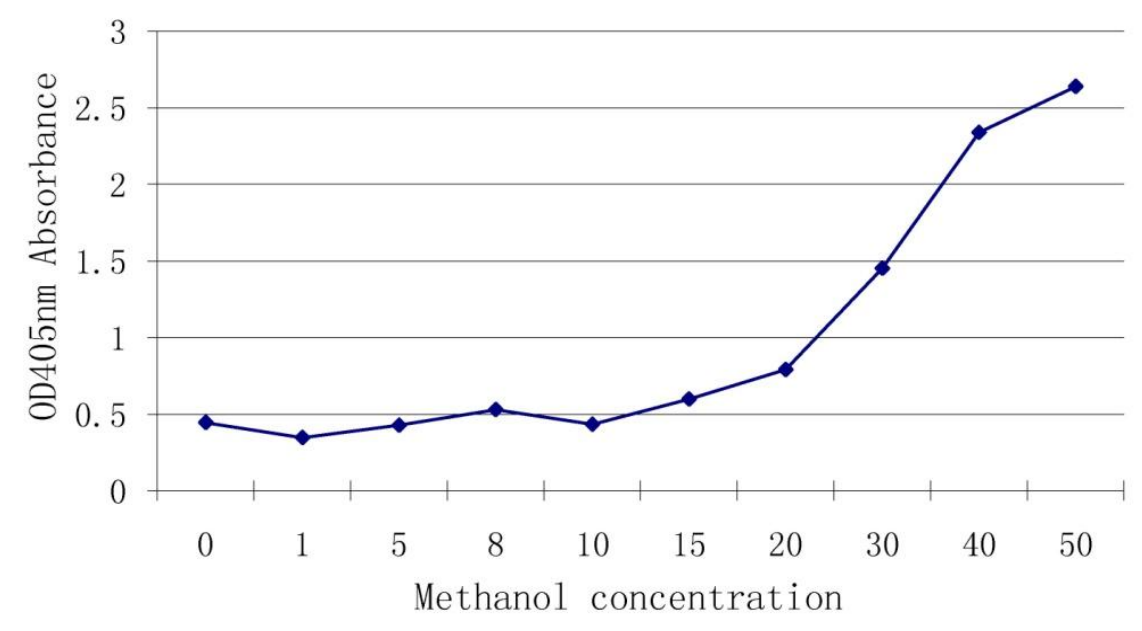

\subsection{Standard Curve}

As shown in Figure 3, when the concentration of DON is $0.001 \mu \mathrm{g} / \mathrm{mL}$ to $1000 \mu \mathrm{g} / \mathrm{mL}$, the equation of inhibition and $\operatorname{LgC}(Y)$ is $Y=0.3855+0.2075 X+0.0097 X^{2}+0.0088 X^{3}, R^{2}=0.9985$. When the concentration of DON is $0.01 \mu \mathrm{g} / \mathrm{mL}$ to $100 \mu \mathrm{g} / \mathrm{mL}$, the linear equation is $Y=0.4057+0.1771 X$, $R^{2}=0.9915$. The detection limit $\left(\mathrm{IC}_{10}\right)$ is $0.02 \mu \mathrm{g} / \mathrm{mL}$. 
Figure 3. The Standard Curve for DON ELISA.

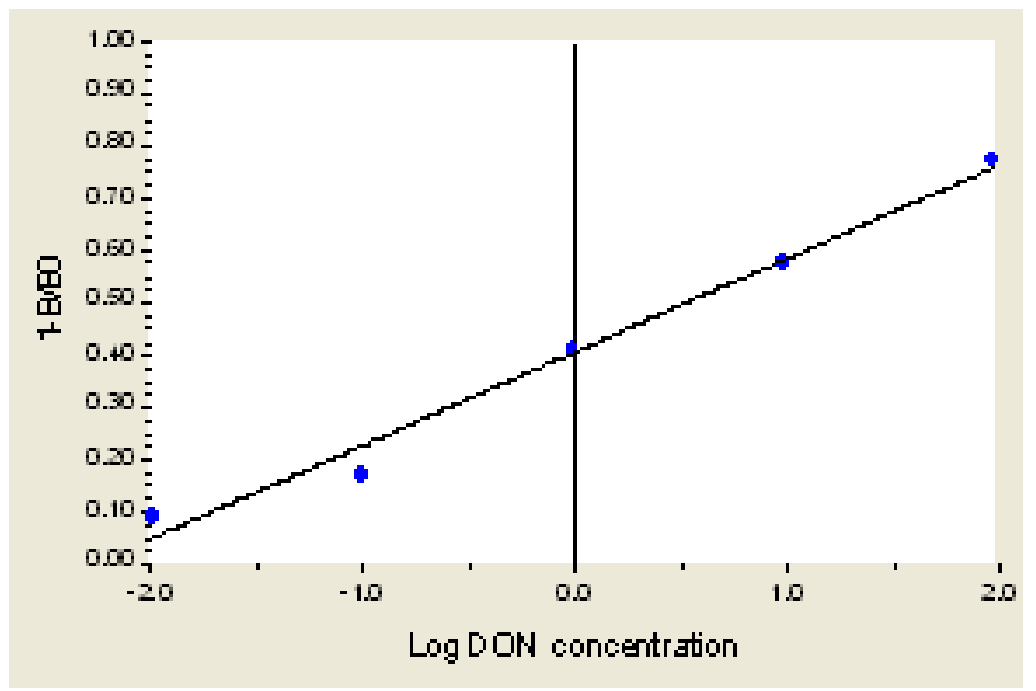

\subsection{Recovery Test}

To determine the precision of the DON ELISA reaction in simulated grain conditions, we added different concentrations of DON in non-contaminated clean wheat, and performed ELISA tests using our optimized conditions of $10 \%$ methanol extraction and 1/1500 coated antigen plates. Under our conditions, the ELISA technique showed (Table 2) a recovery of DON from $82 \%$ to $93 \%$.

Table 2. ELISA recovery of DON from artificially contaminated wheat sample.

\begin{tabular}{ccc}
\hline Added DON $(\boldsymbol{\mu g} / \mathbf{g})$ & DON Detected $(\boldsymbol{\mu g} / \mathbf{g})$ & Recovery \\
\hline 0.5 & $0.43 \pm 0.02$ & $86 \%$ \\
10 & $9.3 \pm 1.1$ & $93 \%$ \\
200 & $164 \pm 35$ & $82 \%$ \\
\hline
\end{tabular}

\subsection{Specificity}

In order to determine the cross-reactivity of Type A and Type B trichothecenes to 3-HS-DON-BSA, we tested a series of concentrations of each trichothecene. Results showed that the $\mathrm{IC}_{50}$ (half-maximal inhibitory concentration) of DON was $6.3 \mu \mathrm{g} / \mathrm{mL}$, for 3Ac-DON it was $114 \mu \mathrm{g} / \mathrm{mL}$, for T2-toxin (a Type A trichothecene) it was higher than $1000 \mu \mathrm{g} / \mathrm{mL}$, and for $15 \mathrm{Ac}-\mathrm{DON}$ it was $>1000 \mu \mathrm{g} / \mathrm{mL}$.

\subsection{DON Detection in Sample}

We then used our ELISA technique to measure the amount of DON found in FHB-infected wheat samples isolated from four different varieties of wheat.

One of the varieties, Ningmai6, was susceptible to FHB while Yangmai 158 showed partial resistance, and two, Sumai3 and Wangshuibai, showed moderate to high resistance to FHB. The amount of DON present in the samples (Table 3), correlated with resistance, in that the better the resistance to FHB, the lower the levels of DON. 
Table 3. DON Detection in different FHB resistant wheat variety with ELISA.

\begin{tabular}{ccc}
\hline Wheat Variety & FHB Resistance & DON $(\boldsymbol{\mu g} / \mathbf{g})$ \\
\hline Sumai3 & Resistant & 3.98 \\
Wang shuibai & Resistant & 2.5 \\
Yangmai158 & Middle & 39.8 \\
Ningmai6 & Susceptible & 63.1 \\
\hline
\end{tabular}

\section{Discussion}

\subsection{Emulsification}

To reduce the immunogenic response in the inoculated animal, the antigen was emulsified well with adjuvant. Emulsification can be done using two possible methods, one is emulsification with a mortar and pestle, while the other one is emulsification with an injector. Although the former is easier to do, significant amounts of antigen, as much as $60-70 \%$, may be bound and this process may also cause contamination with many microbes [22], so this method is not suitable for rare antigens. We chose the injector emulsification technique, as it produced a more stable solution that did not result in a significant loss of the antigen.

\subsection{Immune Animal and Method}

To obtain high titration and high specificity of the antibody, it is necessary to have a good antigen and an animal capable of a suitable immune response. In this study, we selected BALB/c mice and guinea pigs as the immune animals. We found the titers of antiserum from BALB/c mice to be higher than that from guinea pigs. It is not sure why this happened. Chen et al. (1998) suggested that an injection intradermally at multiple sites on the back was preferable [23]. When we tried this method in this study, we found it produced many sores on the animals' back after injection and deduced this may have disturbed the production of antibody. Additionally, we found that intraperitoneal booster inoculations were much easier than the intradermal method.

\subsection{Cross-Reactivity}

Cross-reactivity (CR) to other trichothecenes is a concern when field grains are to be tested for DON. The antibody we obtained did not bind 15Ac-DON and cross-reacted with 3Ac-DON at a 55.2\% level. Both 3Ac-DON and 15Ac-DON, as well as DON, are often detected in FHB-contaminated grains, but at low levels [24,25]. Indeed, detection of both acetylated versions of DON in a grain sample would be beneficial, as Alexander et al. [26] have shown that the acetylated versions of DON are precursors to the end-product of DON.

Our CR results differ from that of Casale et al. [18] (1988) who reported that their antibody to 3-HS-DON-OA actually had a higher affinity to 3Ac-DON than to DON. Schneider et al. [16] summarized several reports to show that 3Ac-DON generally has a stronger reaction than 15Ac-DON. This indicates that an antigen may induce antibodies that react in slightly different ways. Our result, as well as those from others, show very low cross-reaction of T-2 toxin, a type A trichothecene, with DON-induced antibodies. 


\subsection{Extraction of DON}

The extraction and detection of DON in a grain sample should be as easy as possible. Solvents containing water can easily extract the water-soluble trichothecene DON. We found that the solvent containing $10 \%$ methanol and $90 \%$ water gave the best recovery of toxin.

\subsection{FHB-Resistant Wheat Cultivars}

Resistance in wheat to FHB is not well understood but resistance in Sumai3 may be correlated with a C-3-glycosyl transferase [27]. The addition of an acetyl group to the C3 position of a trichothecene has been shown to reduce toxicity [28]. If resistant wheat lines are less susceptible to Fusarium infection, one would expect less visible disease symptoms and less DON production. Any DON produced may also be acetylated at the $\mathrm{C}-3$ position and may not be detected in this ELISA assay. However, our results do show the correlation of reduced DON with reduced disease.

\section{Conclusions}

In this study, we made 3HS-DON-BSA conjugated DON antigen and injected BALB/c mice and guinea pigs by two different immunization methods and obtained high titers of antiserum to DON. In our system, the optimized working concentrations were 1:1500 of coating-antigen to 1:1600 of antiserum. Concentration of methanol for DON extraction of lower than $15 \%$ had little effect on the reaction. In this indirect ELISA assay, the percentage of CR of 3-Ac-DON and T-2 toxin was 55.2\% and $6.3 \%$ respectively and the limit of detection was $0.01-100 \mu \mathrm{g} / \mathrm{mL}$. Average recovery of DON from contaminated grain was $82 \%-93 \%$. Using this method, we detected DON in field samples of wheat and found that the amount of DON correlated with the resistance to FHB.

\section{Acknowledgements}

This study was funded by National Special Project (2009ZX08011-015B), National Science Foundation of China (30901006), Jiangsu Social Development Foundation (BE2010757), and Jiangsu Agricultural Science Initiative (CX(10)235).

\section{References}

1. Council for Agricultural Science and Technology. Mycotoxins: Risks in Plants, Animals and Human Systems; Report No. 139; Council for Agricultural Science and Technology: Ames, IA, USA, January 2003.

2. McMullen, M.; Jones, R.; Gallenberg, D. Scab of wheat and barley: A re-emerging disease of devastating impact. Plant Dis. 1997, 81, 1340-1348.

3. Foroud, N.A.; Eudes, F. Trichothecenes in cereal grains. Int. J .Mol. Sci. 2009, 10, 147-173.

4. Ueno, Y.; Hosoya, M.; Morita, Y.; Ueno, I.; Tatsuno, T. Inhibition of the protein synthesis in rabbit reticulocyte by nivalenol, a toxic principle isolated from Fusarium nivale-growing rice. J. Biochem. 1968, 64, 479-485. 
5. Rotter, B.A.; Prelusky, D.B.; Pestka, J.J. Toxicology of deoxynivalenol (vomitoxin). J. Toxicol. Environ. Health 1996, 48, 1-34.

6. Pestka, J.J.; Zhou, H.R.; Moon, Y.; Chung, Y.J. Cellular and molecular mechanisms for immune modulation by deoxynivalenol and other trichothecenes: Unraveling a paradox. Toxicol. Lett. 2004, 153, 61-73.

7. U.S. Food and Drug Administration, Center for Food Safety and Applied Nutrition. Guidance for Industry and FDA: Letter to State Agricultural Directors; State Feed Control Officials, and Food, Feed and Grain Trade Organizations, 1993. Available online: http://www.cfsan.fda.gov/_dms/ graingui.html (accessed on 26 April 2006).

8. Ueno, Y.; Sato, N.; Ishii, K.; Sakai, K.; Tsunoda, H. Biological and chemical detection of trichothecene mycotoxins of Fusarium species. Appl. Microbiol. 1973, 25, 699-704.

9. Ueno, Y.; Nakajima, M.; Sakai, K.; Ishii, K.; Sato, N. Comparative toxicology of trichothec mycotoxins: Inhibition of protein synthesis in animal cells. J. Biochem. 1973, 74, 285-296.

10. Council for Agricultural Science and Technology. Mycotoxins: Risks in Plants, Animals and Human Systems; Report No. 139; Council for Agricultural Science and Technology: Ames, IA, USA, January 2003; p. 1999.

11. Scott, P.M.; Kanhere, S.R. Comparison of column phases for separation of derivatized trichothecenes by capillary gas chromatography. J. Chromatogr. 1986, 368, 374-380.

12. Acke, B.K.; Casper, H.H. Determination of Deoxynivalenol in wheat, barley, and malt by column cleanup and gas chromatography with electron capture detection. J. AOAC Int. 1996, 79, $472-475$.

13. Trucksess, M.W.; Page, S.W.; Wood, G.E.; Choth, T.H. Determination of Deoxynivalenol in white flour, whole wheat flour, and bran by solid-phase extraction/liquid chromatography: Interlaboratory study. J. AOAC Int. 1998, 81, 880-886.

14. Jestoi, M.; Ritieni, A.; Rizzo, A. Analysis of the Fusarium mycotoxins fusaproliferin and trichothecenes in grains using gas chromatography-mass spectrometry. J. Agric. Food. Chem. 2004, 52, 1464-1469.

15. Klotzel, M.; Gutsche, B.; Lauber, U.; Humpf, H.U. Determination of 12 type A and B trichothecenes in cereals by liquid chromatography-electrospray ionization tandem mass spectrometry. J. Agric. Food. Chem. 2005, 53, 8904-8910.

16. Schneider, E.; Curtui, V.; Seidler, C.; Dietrich, R.; Usleber, E.; Märtlbauer, E. Rapid methods for deoxynivalenol and other trichothecenes. Toxicol. Lett. 2004, 153, 113-121.

17. Barna-Vetro, I.; Gyongyosi, A.; Solt, L. Monoclonal antibody-based enzyme-linked immunosorbent assay of Fusarium T-2 and zearalenone toxins in cereals. Appl. Environ. Microbiol. 1994, 60, 729-731.

18. Casale, W.L.; Pestka, J.J.; Hart, L.P. Enzyme-linked immunosorbent assay employing monoclonal antibody specific for Deoxynivalenol (vomitoxin) and several analogues. J. Agric. Food. Chem. 1988, 36, 663-668.

19. Abraham, G.E. Radioimmunoassay of steroids in biological fluids. J. Steroid Biochem. 1975, 6, 261-270.

20. Park, J.J.; Chu, F.S. Assessment of immunochemical methods for the analysis of trichothecene mycotoxins in naturally occurring moldy corn. J. AOAC Int. 1996, 79, 465-471. 
21. Pestka, J.J.; Islam, Z.; Amuzie, C.J. Immunochemical assessment of Deoxynivalenol tissue distribution following oral exposure in the mouse. Toxicol. Lett. 2008, 178, 83-87.

22. Yang, L.G.; Hu, S.C.; Wei, P.H. Technology of Immunoassay; Nanjing University Press: Nanjing, China, 1998; pp. 279-284 (in Chinese).

23. Chen, X.J.; Chen, M.Y.; Zhao, Y.J. Application of Immunological Techniques in Plant Science; China Agricultural University Press: Beijing, China, 1998 (in Chinese).

24. Wang, Y.Z.; Miller, J.D. Toxin producing potential of Fusarium graminearum from China. MycoSystema 1994, 13, 229-234 (in Chinese).

25. Bottalico, A.; Perrone, G. Toxigenic Fusarium species and mycotoxins associated with head blight in small-grain cereals in Europe. Eur. J. Plant Pathol. 2002, 108, 611-624.

26. Alexander, N.J.; McCormick, S.P.; Waalwijk, C.; Lee, T.; Proctor, R.H. The genetic basis for 3-ADON and 15-ADON trichothecene chemotypes in Fusarium. Fungal Genet Biol. 2011, 48, 485-495.

27. Lemmens, M.; Scholz, U.; Berthiller, F.; Dall'Asta, C.; Koutnik, A.; Schuhmacher, R.; Adam, G.; Buerstmayr, H.; Mesterhazy, A.; Krska, R.; Ruckenbauer, P. The ability to detoxify the mycotoxin deoxynivalenol colocalizes with a major quantitative trait locus for Fusarium head blight resistance in wheat. Mol. Plant Microbe Interact. 2005, 18, 1318-1324.

28. Alexander, N.J.; McCormick, S.P.; Ziegenhorn, S.L. Phytotoxicity of selected trichothecenes using chlamydomonas reinhardtii as a model system. Nat. Toxins 1999, 7, 265-269.

(C) 2011 by the authors; licensee MDPI, Basel, Switzerland. This article is an open access article distributed under the terms and conditions of the Creative Commons Attribution license (http://creativecommons.org/licenses/by/3.0/). 